\title{
Star anise extracts modulation of reproductive parameters, fertility potential and DNA fragmentation induced by growth promoter Equigan in rat testes
}

\author{
Thanaa Ahmed Elmasry ${ }^{1}$, Nora Hamed Al-Shaalan ${ }^{3}$, Ehab Tousson ${ }^{4 *}$, \\ Kadreya El-Morshedy ${ }^{1,5}$, Areej Al-Ghadeer ${ }^{2}$
}

\begin{abstract}
${ }^{I}$ Pharmaceutical Science Department, Faculty of Pharmacy, Princess Nourah bint Abdulrahman University, Riyadh, Saudi Arabia, ${ }^{2}$ Pharmaceutical Practice Department, Faculty of Pharmacy, Princess Nourah bint Abdulrahman University, Riyadh, Saudi Arabia, ${ }^{3}$ Chemistry Department, Faculty of Science, Princess Nourah bint Abdulrahman University, Riyadh, Saudi Arabia, ${ }^{4}$ Department of Zoology, Faculty of Science, Tanta University, Tanta, Egypt, ${ }^{5}$ Anatomy and Embryology Department, Faculty of Medicine, Tanta University, Tanta, Egypt
\end{abstract}

\begin{abstract}
Equigan is an anabolic steroid that has been developed for veterinary use and derived from endogenous sex hormone testosterone that plays a key role in the development of male reproductive tissue as well as in puberty and spermatogenesis. The current study is aimed to investigate the possible prophylactic effect of star anise extracts (SAE) on the toxicity of rat testes, sexual hormones alternations, sperm count, sperm abnormalities and testicular DNA damage by Equigan. Forty adult male rats were equally divided into four groups $\left(1^{\text {st }}\right.$ Control group, $2^{\text {nd }} \mathrm{SAE}$ group, $3^{\text {rd }}$ Equigan and $4^{\text {th }}$ Equigan $+\mathrm{SAE}$ group $)$. Food and fluid intakes, relative body weight, potassium, chloride, phosphorous, non-progressive and immotile sperms were significantly increased in Equigan group as compared to control group. In contrast; relative testes weight, sodium, magnesium, total calcium, testosterone, FSH, LH, PRL, sperm count, progressive motility, and viability showed a significant decrease in Equigan group as compared to control groups. The relative weight of epididymis, seminal vesicles, prostates and serum calcium ions didn't change significantly in different studied groups. Co-administration of SAE with Equigan improved the sexual toxicity, electrolyte alternations, sperm count, abnormalities and DNA damage induced by Equigan.
\end{abstract}

Keywords: Anabolic steroid/Equigan. Testis/secretion. Spermatogenesis/drug effects. Sperm Marphometery. Anabolic Agents/pharmacology. Star anises/drug effects. Illicium verum/drug effects. Reproductive Control Agents/pharmacology. Fertility Agents, Male/analysis. DNA Fragmentation/ drug effects.

\section{INTRODUCTION}

Anabolic-androgenic steroids are defined as synthetic derivatives of the endogenous sex hormone testosterone that plays a key role in the development of male reproductive tissue (such as the testis and prostate) as well as in puberty, sexual behavior, spermatogenesis and plays promoting secondary sexual characteristics such as increased muscle, bone mass and hair growth (Mitchell et al., 2009; Balthazart, Ball, 2010; Mohammed et al., 2016). Anabolic steroids are

\footnotetext{
*Correspondence: E. Tousson. Department of Zoology, Faculty of Science, Tanta University, Tanta, Egypt. Mobile: 00201002282382. E-mail: toussonehab@yahoo.com
}

forbidden for meat production and human use in KAS, and most countries worldwide due to their undesirable effects included blood and cardiovascular disorders (Santos et al., 2006; Tousson et al., 2016; Waljee et al., 2016), liver dysfunction (Van Amsterdam et al., 2010; Barakat et al., 2015), kidney disease (Barakat et al., 2015), tendon damage (Battista, Combs, Warne, 2003), testicular problems (Tousson et al., 2012; 2016; El-Masry et al., 2017), psychiatric and behavioural disorders in both sexes (Salas-Ramirez, Montalto, Sisk, 2010), as well as other problems on the human body (Saleh, Waded, 2014).

Equigan is an anabolic steroid that is developed for veterinary use to improve the food-producing animal growth rate through promoting protein synthesis 
(Mottram, George, 2000; Zahran, Tousson, Shalapy, 2015) and also Equigan have been reclassified as Schedule III drugs and in addition, it is classified as class 2A (growth promoters-steroids according to the International Agency for Research on Cancer; ISRC), as a probable human carcinogen with a high carcinogenic index (WHO, 1987). Recently, in order to get a better physical performance and muscular appearance, many young people seek resources that, in most cases, can bring harm to health, such as the indiscriminate use of Equigan.

Star anise (Illicium verum) is an aromatic evergreen tree that grows in China and Vietnam and is traditionally used in the treatment of stomach aches, insomnia, vomiting, inflammation and rheumatic pain (Itoigawa et al., 2004; Chinese Pharmacopoeia 2010).

Star anise crude extracts possess wide pharmacological properties, such as an antioxidant, by reducing free radical production and lipid peroxidation and antimicrobial; additionally, it is considered as the main source of shikimic acid, which is a primary ingredient of the Tamiflu drug (Singh et al., 2006; Wang et al., 2011). Therefore, the aim of the current study was to investigate the possible prophylactic effect of star anise extracts (SAE) on the toxicity of the rat testes, sexual hormones alternations, sperm count, sperm abnormalities and testicular DNA damage by Equigan.

\section{MATERIALS AND METHODS}

\section{Chemical and reagent}

Equigan ${ }^{\circledR}$ vial was obtained from Laboratorios Tornel Co., (S.A. Mexico). Each vial containing oily solution (50 $\mathrm{mg} / \mathrm{mL}$ vehicle).

\section{Experimental animals}

Healthy male albino rats (weighing 180-200 g and 12-14 weeks of age), supplied from the accredited breeding and experimental laboratory (Tanta Alpha Center, Egypt) were used for this study. The animals had free access to water. Rats were monitored closely during the treatment period (12 weeks). The food intake, fluid intake and body weight were recorded weekly throughout the experimental period. All the experiments were designed and conducted according to the ethical norms approved by the Ethical Committee of National Research Center. The experimental procedures were approved by the Committee of Ethics in the Use of Experimental Animals-ENRC (Protocol no. 039/2008).

\section{Experimental design}

After 2 weeks of acclimatization, rats were assigned to 4 groups (10 animals each) as follows:

Control group; in which rats will not receive any treatment.

Star anise group; in which rats will receive orally star anise extract (SAE) by stomach tube $(100 \mathrm{mg} / \mathrm{kg}$ $\mathrm{BW} /$ twice a week) for 12 weeks according to Wang et al. (2011).

Equigan group; in which rats will injected intramuscular with Equigan $(5 \mathrm{mg} / \mathrm{kg} \mathrm{BW} \backslash$ week) for 12 weeks according to Zahran et al. (2015) and El-Masry et al 2017.

Treated Equigan with SAE group; in which rats will receive intramuscular injections of Equigan at $(5 \mathrm{mg} /$ $\mathrm{Kg}$ body weight $/$ week) with oral SAE $(100 \mathrm{mg} / \mathrm{kg}$ body weight/ twice a week) together for 12 weeks according to El-Masry et al 2017.

At the end of the experimental period, rats from each group were euthanized with anesthetic ether and subjected to a complete necropsy after 10-12 h of fasting. Blood samples were collected from the inferior vena cava of each rat in non-heparinized glass tubes. Blood serum was separated, collected and stored at $-18{ }^{\circ} \mathrm{C}$. Testes, epididymis, seminal vesicles and prostates were removed, carefully cleaned in cold saline and weighed.

\section{Clinical chemistry}

Total calcium levels in serum were determined by using commercial kits (Bicon Co, Germany) according to the method of Schmidt et al. (2002) while magnesium levels in serum were determined by using commercial kits (BioMérieux Co, France) according to the method of Henry et al. (1974). Serum potassium, sodium, calcium and chloride ion levels were determined by using commercial kits (Sensa core electrolyte, India).

\section{Hormone assay}

Prolactin levels in rat serum were assayed by using the ADVIA Centaur XP system (two-site sandwich immunoassay using direct chemiluminometric technology; Vidas, France). The $1^{\text {st }}$ antibody, in the Lite Reagent, is a polyclonal goat anti-prolactin antibody labeled with acridinium ester. The second antibody, in the solid phase, is a monoclonal mouse anti-prolactin antibody, which is covalently coupled to paramagnetic particle.

Luteinizing hormone (LH) levels in rat serum were assayed by using the ADVIA Centaur XP system (two-site sandwich immunoassay using direct chemiluminometric technology; Vidas, France). The $1^{\text {st }}$ antibody is a 
monoclonal mouse anti-LH antibody labeled with acridinium ester. The second antibody, in the solid phase, is a monoclonal mouse anti-LH antibody, which is covalently coupled to paramagnetic particles.

Follicle stimulating hormone (FSH) levels in serum were assayed by using the ADVIA Centaur XP system (two-site sandwich immunoassay using direct chemiluminometric technology; Vidas, France). The $1^{\text {st }}$ antibody is a polyclonal sheep anti-FSH antibody bound to monoclonal mouse anti-FSH antibody, coupled to paramagnetic particles in the solid phase.

Total testosterone concentrations in serum were assayed by using the ADVIA Centaur XP system (two-site sandwich immunoassay using direct chemiluminometric technology; Vidas, France). Testosterone in the rats sample competes with acridinium ester-labeled testosterone in the reagent for a limited amount of polyclonal rabbit antitestosterone antibody bound to monoclonal mouse antirabbit antibody, and coupled to paramagnetic particles in the solid phase.

\section{Sperms morphometric analysis}

The left caudal part of the epididymis was carefully separated from each testis, finely minced in $5 \mathrm{ml}$ of Hanks' buffered salt medium, and incubated at room temperature for $15 \mathrm{~min}$ to provide the migration of all spermatozoa from epididymal tissue to fluid. To evaluate sperm count, spermatozoa motility parameters and sperm morphology computer assisted semen analysis (CASA System; MiniTüb, Germany) with Olympus microscope (Olympus, Tokyo, Japan) was used according to the method of Adamkovicova et al. (2016).

Assessing the spermatozoa morphological abnormalities, after semen collection, samples were fixed with Hancock's solution, smears were prepared on a slide, and air-dried and made permanent as smeared slide was stained with 1\% eosin Y and 5\% nigrosin. Morphological sperm defects were evaluated and examined on Olympus microscope using $400 \times$ magnification. A total of 200 spermatozoa from each rat were examined and individually scored normal or abnormal, according to the strict sperm morphology criteria by Wang et al. (2016).

\section{DNA fragmentation}

DNA damage in testis from different groups was tested by using the diphenylamine (Saggu et al., 2014). The percentage of DNA fragmentation in each sample was expressed by the following formula:

$\%$ DNA fragmentation $=($ O.D. Supernatant $/$ O.D. Supernatant + O.D. pellet $) \times 100$. (O.D. is optical density)

\section{Statistical analysis}

Data were expressed as mean values $\pm \mathrm{SE}$ and statistical analysis was performed using one way ANOVA to assess significant differences among treatment groups. The criterion for statistical significance was set at $p<0.01$ for the biochemical data. All statistical analyses were performed using SPSS statistical version 21 software package (SPSS ${ }^{\circledR}$ Inc., USA).

\section{RESULTS}

Table I showed that food, fluid intakes and relative body weight (RBW) showed a significant increase in Equigan group as compared to control and SAE groups. Meanwhile, relative testes weight showed a significant decrease in Equigan group as compared to control and SAE groups. On the other hand, the relative weight of epididymis, seminal vesicles and prostates did not change significantly in different studied groups (Table I).

\section{Effect of Equigan and SAE on electrolytes alterations}

Table II showed the changes in the serum sodium, potassium, calcium, chloride, magnesium and phosphorous levels in different groups under study. Serum sodium, magnesium and total calcium levels were significantly decreased in Equigan group as compared to control and SAE groups. In contrast, serum potassium, chloride and phosphorous were significantly increased in Equigan group as compared to control and SAE groups. On the other hand, there was a significant increase in serum sodium, magnesium and total calcium levels in cotreatment Equigan with SAE group when compared with Equigan group, while there was a significant decrease in serum potassium, chloride and phosphorous levels in cotreatment Equigan with SAE group when compared with Equigan group (Table II). In addition, serum calcium ions didn't change significantly in different studied groups (Table II).

\section{Effect of Equigan and SAE on reproductive hormones}

Figures 1 and 2 showed the changes in total testosterone, $\mathrm{FSH}, \mathrm{LH}$ and PRL hormone levels in different groups under study. Testosterone, FSH, LH and PRL levels were significantly decreased in Equigan group as compared to control and SAE groups. In contrast, there was a significant increase in total testosterone, FSH, LH 
TABLE I - Changes in the water intake, Food intake, relative body weights (RBW) and relative organ weights (g/100 g body weight) of sex organs in different groups

\begin{tabular}{lcccc}
\hline & Control & SAE & Equigan & Equigan+SAE \\
\hline $\begin{array}{l}\text { Water intake (ml/rat/ } \\
\text { day) }\end{array}$ & $35.5^{*} \pm 1.98$ & $35.9^{*} \pm 2.50$ & $42.4^{*} \pm 1.44$ & $39.8^{*} \pm 2.62$ \\
Food intake (g/rat/day) & $13.4^{\#} \pm 0.57$ & $13.8^{\#} \pm 0.95$ & $19.0^{*} \pm 0.58$ & $16.9^{* *} \pm 0.44$ \\
RBW (g/100 g) & $26.5^{\#} \pm 1.03$ & $29.8^{*} \pm 0.89$ & $47.2^{*} \pm 2.21$ & $36.8^{* *} \pm 1.25$ \\
RTW (g/100 g) & $1.34^{\#} \pm 0.045$ & $1.37^{\#} \pm 0.029$ & $1.09^{*} \pm 0.032$ & $1.26^{* *} \pm 0.081$ \\
REW (g/100 g) & $0.332 \pm 0.046$ & $0.335 \pm 0.022$ & $0.330 \pm 0.018$ & $0.335 \pm 0.048$ \\
RPW (g/100 g) & $0.310 \pm 0.018$ & $0.316 \pm 0.015$ & $0.309 \pm 0.011$ & $0.311 \pm 0.027$ \\
RSWW (g/100 g) & $0.44 \pm 0.076$ & $0.43 \pm 0.061$ & $0.42 \pm 0.045$ & $0.42 \pm 0.07$ \\
\hline
\end{tabular}

Value represents mean \pm SE of 10 rats. Significant difference from the control group at $* p<0.05$. Significant difference from Equigan group at ${ }^{\#} p<0.05$. Relative testes weights (RTW), relative Epididymis weights (REW), relative seminal vesicles weights (RSVW) and relative prostates weights (RPW).

$$
\text { Relative organ weight }=\frac{\text { Organ weight }}{\text { Body weight }} \times 100
$$

TABLE II - Changes in electrolyte levels in different groups

\begin{tabular}{lcccc}
\hline & Control & SAE & Equigan & Equigan+SAE \\
\hline $\mathbf{N a}^{+}(\mathbf{m m o l} / \mathbf{L})$ & $135.4 \pm 8.435^{\mathrm{b}}$ & $136.9 \pm 5.266^{\mathrm{b}}$ & $127.1 \pm 4.519^{\mathrm{a}}$ & $143.0 \pm 7.025^{\mathrm{c}}$ \\
$\mathbf{K}^{+}(\mathbf{m m o l} / \mathbf{L})$ & $4.365 \pm 0.198^{\mathrm{b}}$ & $4.410 \pm 0.124^{\mathrm{b}}$ & $5.633 \pm 0.138^{\mathrm{a}}$ & $3.20 \pm 0.119^{\mathrm{b}}$ \\
$\mathbf{C a}^{++}(\mathbf{m m o l} / \mathbf{L})$ & $1.261 \pm 0.094$ & $1.248 \pm 0.055^{\mathrm{b}}$ & $1.211 \pm 0.032$ & $1.239 \pm 0.106$ \\
$\mathbf{C a}$ total $\mathbf{( m g / \mathbf { d L } )}$ & $10.54 \pm 0.329^{\mathrm{b}}$ & $10.61 \pm 0.541^{\mathrm{b}}$ & $9.46 \pm 0.187^{\mathrm{a}}$ & $10.13 \pm 0.615^{\mathrm{ab}}$ \\
$\mathbf{C l}(\mathbf{m m o l} / \mathbf{L})$ & $100.3 \pm 4.35^{\mathrm{b}}$ & $102.0 \pm 8.81^{\mathrm{b}}$ & $119.1 \pm 5.55^{\mathrm{a}}$ & $116.5 \pm 8.46^{\mathrm{a}}$ \\
$\mathbf{M g}(\mathbf{m g} / \mathbf{d L})$ & $2.17 \pm 0.055^{\mathrm{b}}$ & $2.31 \pm 0.028^{\mathrm{b}}$ & $1.13 \pm 0.019^{\mathrm{a}}$ & $1.65 \pm 0.053^{\mathrm{ab}}$ \\
$\mathbf{P h}(\mathbf{m g} / \mathbf{d L})$ & $4.94 \pm 0.18^{\mathrm{b}}$ & $4.87 \pm 0.24^{\mathrm{b}}$ & $7.43 \pm 0.41^{\mathrm{a}}$ & $6.13 \pm 0.155^{\mathrm{ab}}$ \\
\hline
\end{tabular}

Value represents mean \pm SE of 10 rats, Significant difference from the control group at $* p<0.05$. Significant difference from Equigan group at ${ }^{\#} p<0.05$.

and PRL in co-treatment Equigan with SAE group when compared with Equigan group (Figures 1 and 2).

\section{Sperm characteristics}

Semen characteristics were affected after Equigan injection, and were significantly depressed in the sperm count, motility and viability in Equigan group as compared to control group (Tables III and IV). In contrast, there was a significant increase in sperm count, motility and viability in co-treatment Equigan with SAE group when compared with Equigan group (Tables III and IV).

Table IV showed the changes in the epididymal sperm total motility $(\mathrm{PR}+\mathrm{NP})$, progressive motility $(\mathrm{PR})$, non-progressive (NP) and immotile (IM) (\%) in the different groups under study. Progressive motility was significantly decreased in Equigan group as compared to control and SAE groups. In contrast, non-progressive and immotile sperms were significantly increased in Equigan group as compared to control and SAE groups (Table IV). In contrast, non-progressive and immotile sperms showed a significant decrease in co-treatment Equigan with SAE group when compared with Equigan group (Table IV).

Figure 1 shows the sperm head abnormalities of rats treated with Equigan, and the percentage of sperm with head defect (no head) has been increased significantly in the Equigan group as compared with control group; in addition, there was a significant increase in other head defects like amorphous, banana shape, hook less head, pin head sperms in Equigan group as compared with control group. In contrast, there was a significant decrease in sperm head abnormalities in co-treatment Equigan with SAE group when compared with Equigan group (Figure 3). The percentage of sperms with bent mid 

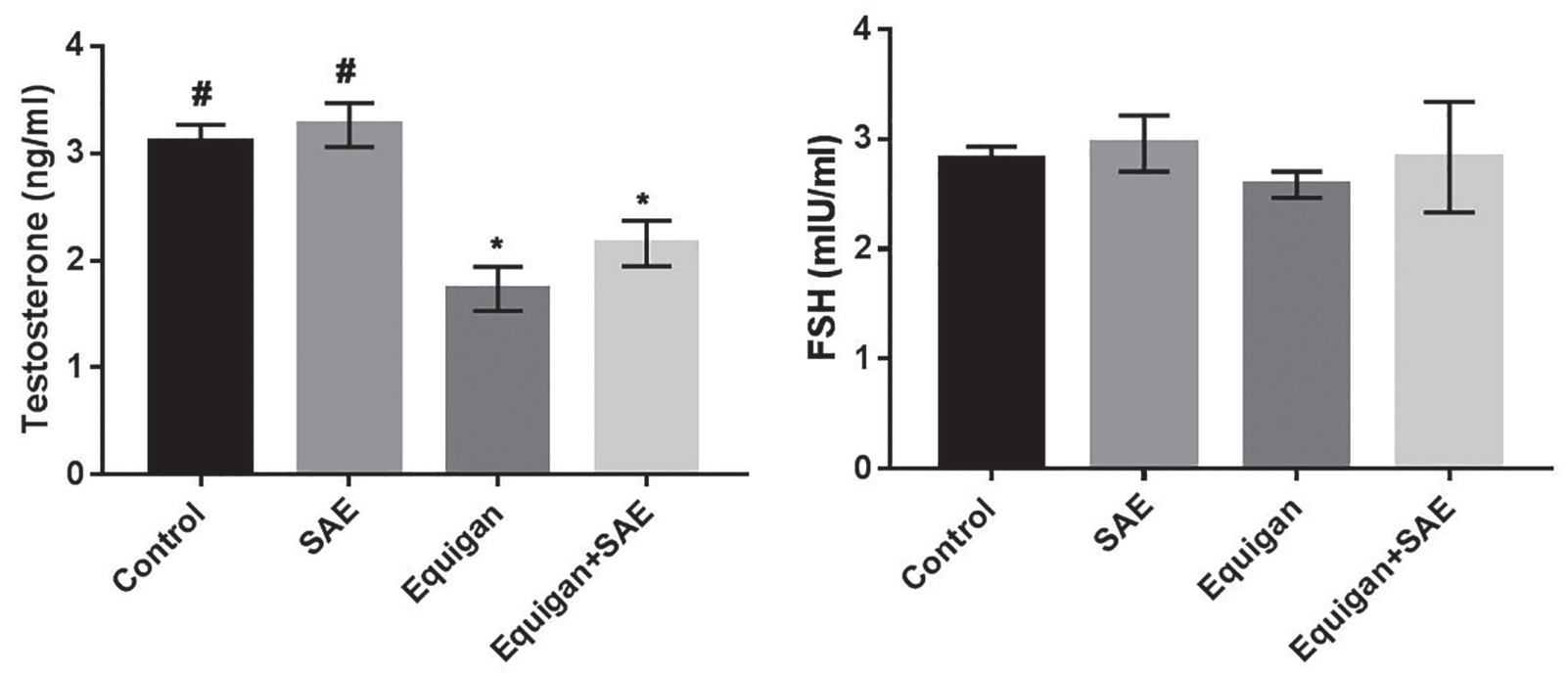

FIGURE 1 - Changes in the total testosterone and Follicle stimulating hormone (FSH) levels in the different groups. (Significant difference from the control group at * $p<0.05$; Significant difference from Equigan group at $\left.{ }^{\#} p<0.05\right)$.
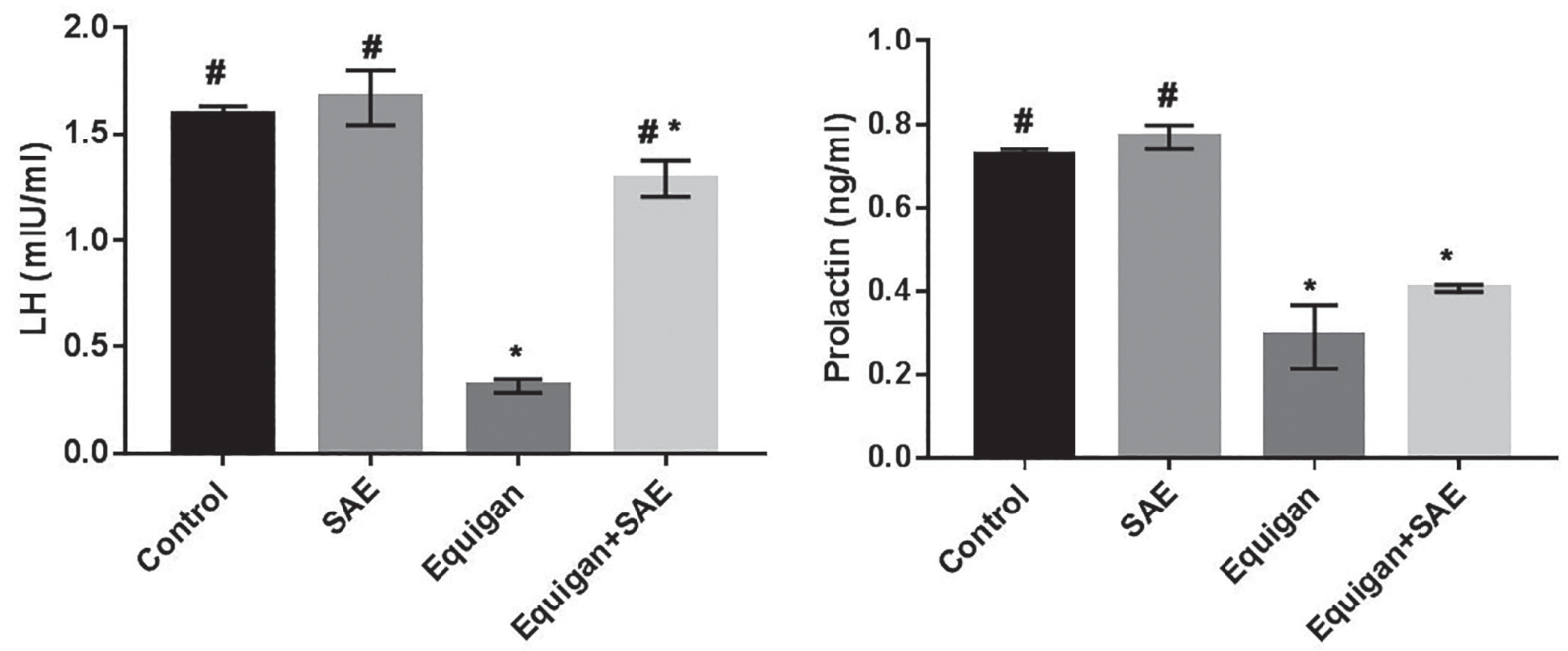

FIGURE 2 - Changes in the Luteinizing hormone (LH) and prolactin (PRL) hormone levels in the different groups. (Significant difference from the control group at * $p<0.05$; Significant difference from Equigan group at ${ }^{\#} p<0.05$ ).

TABLE III - Changes in the epididymal sperm count and vitality in the different groups under study

\begin{tabular}{lcccc}
\hline & Control & SAE & Equigan & Equigan+SAE \\
\hline Sperm count (million/ml) & $81.9^{\#} \pm 8.52$ & $86.1^{\#} \pm 7.35$ & $53.66^{*} \pm 4.21$ & $74.98^{\# *} \pm 8.45$ \\
Vitality (\%) & $79.85^{\#} \pm 3.74$ & $72.05^{\#} \pm 3.11$ & $54.19^{*} \pm 3.46$ & $71.55^{\# *} \pm 5.65$ \\
\hline
\end{tabular}

Each reading represents Mean \pm SEM of 10 rats. The significance of difference was checked by $t$ test and multiple comparison Dunnett test (compare all vs control) using a computer program graph pad (Instat software Inc). Significant difference from the control group at $* \mathrm{p}<0.05$. Significant difference from Equigan group at $\# \mathrm{p}<0.05$.

piece was significantly increased in control rats group as compared with Equigan group while curved mid-piece was significantly increased in Equigan rats group as compared with control group. Also, Figure 3 shows the sperm tail abnormalities or tail defect (as headless, bent, curved, coiled and looped tails) of rats treated with Equigan, which were significantly increased as compared with control group. In contrast, there was a significant decrease 
TABLE IV - Changes in the epididymal sperm total motility (PR+NP), progressive motility (PR), non-progressive (NP) and immotile (IM) (\%) in the different groups under study

\begin{tabular}{lcccc}
\hline & Control & SAE & Equigan & Equigan+SAE \\
\hline Total motility (PR+NP) & $70.05^{\#} \pm 2.69$ & $71.35^{\#} \pm 2.45$ & $58.28^{*} \pm 3.48$ & $66.09^{\# *} \pm 3.39$ \\
Progressive motility (PR) & $47.65^{\#} \pm 2.35$ & $51.23^{\#} \pm 4.37$ & $33.36^{*} \pm 1.75$ & $44.55^{\sharp} \pm 2.15$ \\
Non Progressive (NP) & $22.40^{\#} \pm 1.15$ & $20.12^{\#} \pm 1.07$ & $24.92^{*} \pm 1.33$ & $21.54^{\#} \pm 1.62$ \\
Immotile (IM) & $29.95^{\#} \pm 0.97$ & $28.65^{\#} \pm 1.91$ & $41.72^{*} \pm 2.27$ & $33.91^{\# *} \pm 2.29$ \\
\hline
\end{tabular}

Each reading represents Mean \pm SEM of 10 rats. The significance of difference was checked by $t$ test and multiple comparison Dunnett test (compare all vs control) using a computer program graph pad (Instat software Inc). Significant difference from the control group at $* \mathrm{p}<0.05$. Significant difference from Equigan group at $\# \mathrm{p}<0.05$.

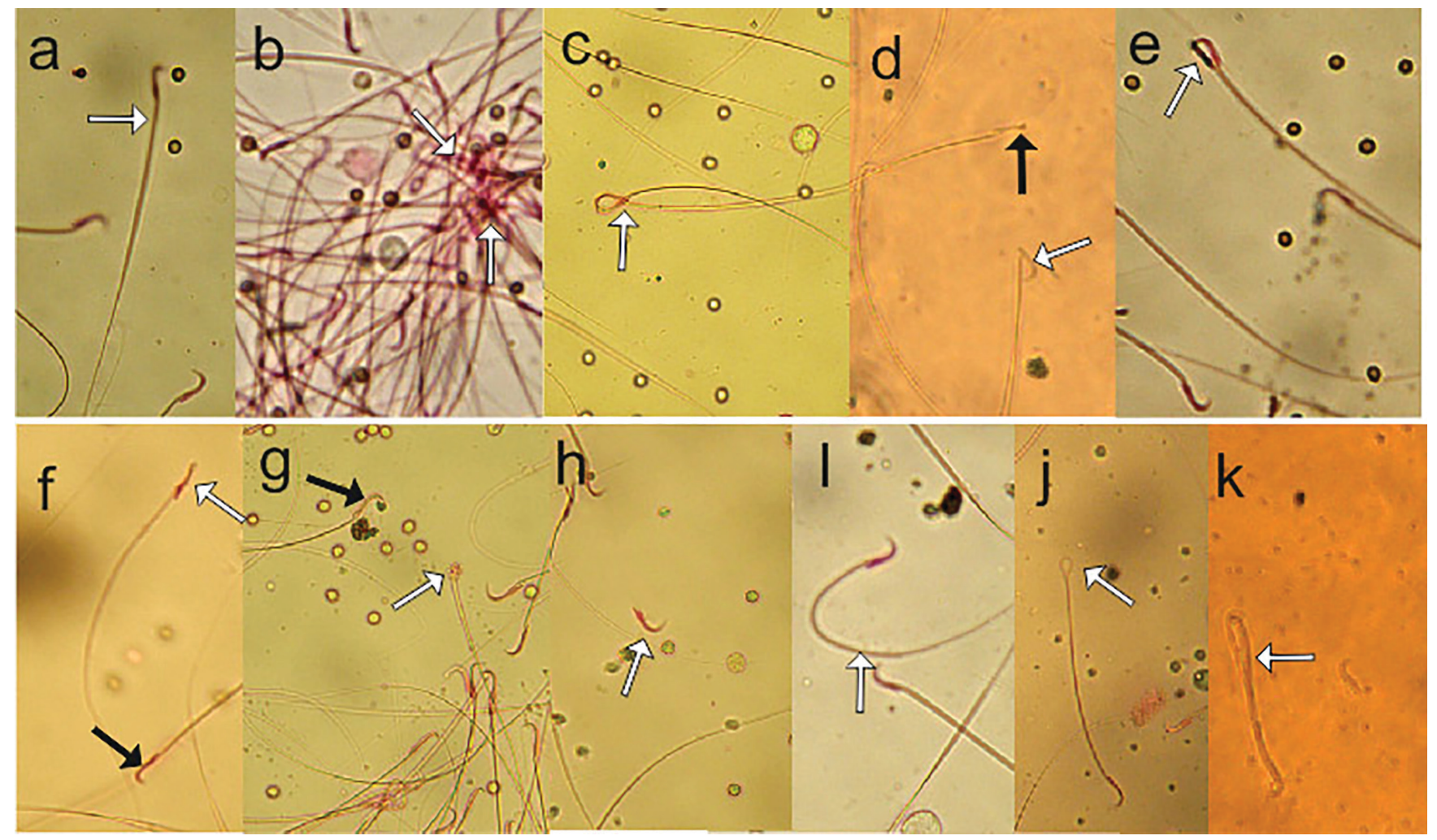

FIGURE 3 - Microphotographs illustrating morphologically normal sperm (a) and various sperm defects (b-K). \{b, Sperm agglutination; c, Fused sperm; d, bent head; e, double head; f, hook less head (white arrow) and hook head (black arrow); g, amorphous head (white arrow) and banana head (black arrow); h, tailless head; I, sperms with bent mid piece; j, coiled tail; k, looped tail\}.

in sperm tail abnormalities in co-treatment Equigan with SAE group when compared with Equigan group.

\section{DNA fragmentation}

In the present study, we found that, intramuscular injections of Equigan to rats resulted in a significant increase in testicular DNA fragmentation $(\mathrm{P}<0.001 \mathrm{vs}$. control group). Treatment with star anise extract inhibited the cellular damage significantly $(\mathrm{P}<0.001)$ (Figure 4).

\section{DISCUSSION}

Anabolic steroid has dual effects on humans (directly and indirectly); directly as intramuscular injection to build muscles and indirectly as through consuming meat of animals that were treated with Equigan (Scarth et al., 2012). The present results revealed that intramuscular injection of the anabolic steroid Equigan to male rats evoked a significant elevation in the food intake, fluid intake and relative body 


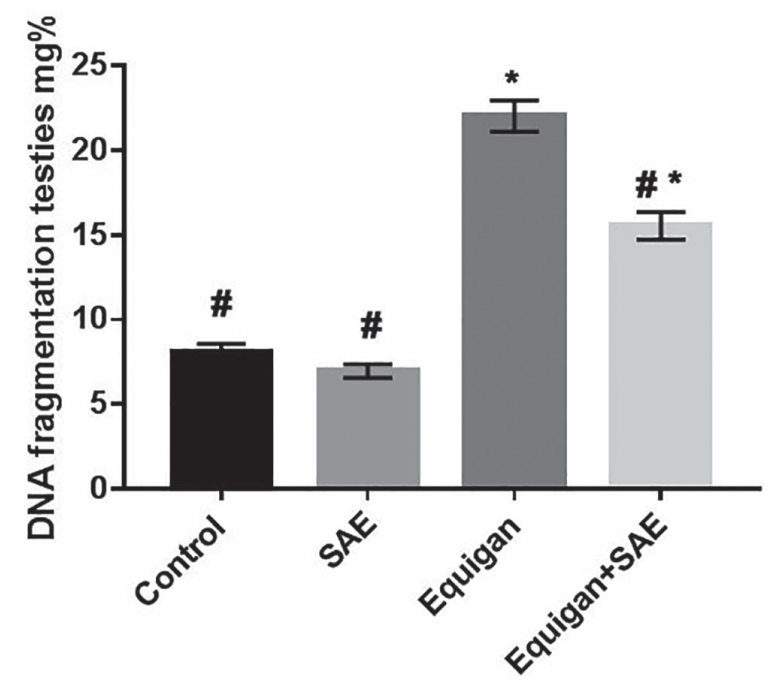

FIGURE 4 - DNA fragmentation in testicular tissues in the different groups under study. (Significant difference from the control group at $* \mathrm{p}<0.05$; Significant difference from Equigan group at $\# \mathrm{p}<0.05)$.

weight rate and a significant depletion in the relative testes weight in Equigan group as compared to control group while the relative weights of epididymis, seminal vesicles and prostates did not reveal any changes between the different groups under study.

Similar findings were reported by Saleh and Waded (2014), El-Moghazy, Tousson, Sakeran (2012) and Mohammed et al. (2016) who reported that the body weight and total protein concentrations in male rabbits were significantly increased after boldenone injections. Also, Silcox, Keeton, Johnson (1986) reported a significant increase in weight gain of lambs after trenbolone acetate injections. In contrast, Cannizzo et al . (2007) found no statistically relevant difference between different groups of veal calves treated with boldenone. The results are not in agreement with Oda and El-Ashmawy (2012) who reported that boldenone had no significant effect on the body weight and body weight gain while the testes and epididymis weights were decreased significantly after boldenone injections in male rabbits. This effect could be attributed to Equigan acting upon the androgen receptors in anabolic-responsive tissues by promoting the body tissue building processes due to increased protein synthesis.

Magnesium ions regulate over 300 biochemical reactions in the body through their role as enzyme cofactors. Chloride ion is an essential electrolyte located in all body fluids responsible for maintaining acid/base balance and transmitting nerve impulses. Also, chloride ion is a chlorine anion that forms the negatively charged part of certain salts, including sodium and hydrogen chloride salts. The present work showed a significant decrease in sodium, magnesium and total calcium levels in Equigan as compared to control groups while there was a significant increase in potassium, chloride and phosphorous in Equigan as compared to control groups. In contrast, Treatment with SAE improved this alteration in electrolytes. These results agree with Pitts and Davis (2007) who reported that an evidence- based analysis of anabolic steroids also enhances performance in horses. Also, the current results agree with Barakat et al. (2015) and El-Masry et al. (2017).

The current results revealed that the level of total testosterone, FSH, LH and PRL hormone dramatically dropped $(\mathrm{P}<0.05)$ in Equigan treated rats group compared with the control group. But rats treated with Equigan and star anise extract (Equigan $+\mathrm{SAE})$ significantly $(\mathrm{p}<0.05)$ increased the level of total testosterone, FSH, LH and PRL hormone compared with Equigan treated rats. This remarkable reduction of sexual hormones which were found in the current study might be explained by severe damages, in which Equigan exerted on Leydig and Sertoli cells by increasing the generation of free radicals, is one of the possible mechanisms involved in anabolic-androgenic steroid-induced Leydig cell degeneration.

In agreement with our findings, Purkayastha and Mahanta (2012) reported a significant decrease in the FSH, LH and testosterone levels after nandrolone decanoate injections in mice. These results agree also with Mohammed et al. (2016), Oda and El-Ashmawy (2012) and Thabet et al. (2010) who reported a significant reduction in the total testosterone after boldenone injections. In contrast, administration of testosterone alone to bull calves did not induce any variation in testosterone (Simontacchi et al., 2004). Also, Shimomura et al. (2005) showed a significant decrease in testosterone levels after ethinylestradiol alone treatment. Not similar findings were reported by Takahashi, Tatsugi, Kohno (2004) and Gabr et al. (2009) who reported that there was a significant increase in serum testosterone levels in treated groups with anabolic-androgenic steroid when compared with control group.

The obtained results indicate that intramuscular injection of rats with Equigan adversely affects spermatogenesis, sperm motility and sperm count suggesting that anabolic-androgenic steroid hormone might play an important role not only in controlling normal testicular development, but also in maintaining normal testicular function and spermatogenesis. This could explain decreased sperm concentration, motility and abnormal morphology induced by Equigan administration 
to rats. The decrease in the sperm count after Equigan intramuscular injection may be due to decreased level of intratesticular testosterone, because testosterone levels are directly linked to spermatogenesis.

Our results agree with Tousson et al. (2012) who reported that boldenone undecylenate affects spermatogenesis by inhibiting the nucleic acid synthesis of germ cells, and reduction in gonadotropin secretion causes atrophy of the testes. Our results were similar to those reported by Ciocca (2005) in athletes and Cannizzo et al. (2007) in veal calves. Also, our results agree with Oda and El-Ashmawy (2012) and Thabet et al. (2010) who reported that there was a significant reduction in the sperm motility and count after boldenone injections while no abnormalities were detected in the sperm morphology after boldenone injections. According to results from the CASA analysis, different motility patterns were identified after Equigan injection. The decrease in normal sperm morphology after Equigan injection was linked to significantly increased sperm with abnormal heads. The decrease in sperm count, the increase in dead and abnormal sperm of rats may occur due to increased free radical formation initiating germ cell apoptosis and subsequent male infertility. On the other hand, the presence of star anise with Equigan improved the sperm motility. However, the incidence and severity of testicular and epididymal lesions in rats pretreated with star anise was considerably ameliorated when compared to that in the Equigan group. Therefore, star anise attenuated the Equigan-induced testis and epididymis damages.

Two main mechanisms are known by which reactive oxygen species (ROS) can cause infertility. In the $1^{\text {st }}$ mechanism, ROS can damage the sperm membrane, which in turn, reduces sperm motility and their ability to fuse with the oocyte, while in the $2^{\text {nd }}$ mechanism, ROS directly damage sperm DNA. The current results revealed that rat injections with Equigan increased testicular DNA fragmentation, and indicated that Equigan is able to induce testicular apoptosis. Our results were in agreement with Meseguer et al. (2008) who reported that DNA damage of sperm cell decrease the quality of the sperm, increase the abnormalities and cause fertilization problems since spermatozoa requires intact DNA during fertilization process. In contrast, SAE improved the testicular DNA damage and this result agree with Dinesha et al. (2014) who studied the antioxidant and DNA protectant activities of star anise aqueous extracts. So, it is therefore possible that SAE could scavenge free radicals and produce beneficial effects against Equigan damage in testis.

\section{ACKNOWLEDGEMENTS}

This work was supported by the Deanship of Scientific Research (DSR), Princess Nourah bint Abdulrahman University, Riyadh, Saudi Arabia, under grant No.37-K-189. The authors therefore, gratefully acknowledge the DSR technical and financial support.

\section{COMPETING INTERESTS}

Authors have declared that no competing interests exist.

\section{ABBREVIATIONS}

SAE, Star anise extracts; PR, Progressive motility of epididymal sperm; NP, non-progressive of epididymal sperm; IM, Immotile sperm; ROS, reactive oxygen species; LH, Luteinizing hormone; FSH, Follicle stimulating hormone; CASA, Computer assisted semen analysis.

\section{REFERENCES}

Adamkovicova M, Toman R, Martiniakova M, Omelka R, Babosova R, et al. Sperm motility and morphology changes in rats exposed to cadmium and diazinon. Reprod Biol Endocrinol. 2016;14(42):1-7.

Balthazart J, Ball GF. Male sexual behavior and hormones in non-mammalian vertebrates. In: Breed MD, Moore J, editors. Encyclopedia of animal behavior. London: Elsevier; 2010. p.340-54.

Barakat LA, Tousson E, IbrahimW, El-Hakeem AA. Role of propolis in improving hepatic and renal damage in boldenone undecylenate in male rats. Am J Biol Chem. 2015;3(1):8-15.

Battista V, Combs J, Warne WJ. Asynchronous bilateral Achilles tendon ruptures and and rostenediol use. Am J Sports Med. 2003;31(6):1007-9.

Cannizzo TF, Zancanaro G, Spada F, Mulasso C, Biolatti B. Pathology of the testicle and sex accessory glands following the administration of boldenone and boldione as growth promoters in veal calves. J Vet Med Sci. 2007;69(11):1109-16.

Chinese Pharmacopoeia. 2010.ed. Beijing: China Medical Science and Technology Press; 2010. p.4-5. [Editorial Committee of Chinese Pharmacopoeia]. 
Ciocca M. Medication and supplement use by athletes. Clinics in Sports Med. 2005;24(3):719-38.

Dinesha R, Thammannagowda SS, Shwetha KL, Prabhu MSL, Madhu CS, Srinivas L. The antioxidant and DNA protectant activities of Star Anise (Illicium verum) aqueous extracts. J Pharmacogn Phytochem. 2014;2(5):98-103.

El-Masry TA, Al-Shaalan NH, Tousson E, El-Morshedy K, Al-Ghadeer A. P53 expression in response to equigan induced testicular injury and oxidative stress in male rat and the possible prophylactic effect of star anise extracts. Annu Res Rev Biol. 2017;14(1):1-8.

El-Moghazy M, Tousson E, Sakeran MI. Changes in the hepatic and renal structure and function after a growth promoter boldenone injection in rabbits. Anim Biol. 2012;62(2):171-180.

Gabr FI, El-Nour FI, Hayat H., Hassan TA, El-Maaty A, Amal $\mathrm{M}$, et al. Effects of growth promoter boldenone undecylenate on weaned male lambs. Nat Sci. 2009;3(7):61-69.

Henry RJ, Cannon DC, Winkelman JW. Clinical chemistry, principles and techniques. $2^{\text {nd }}$ ed. New York: Harper and Row; 1974. p.525.

Itoigawa M, Ito C, Tokuda H, Enjo F, Nishino H, Furukawa H. Cancer chemopreventive activity of phenylpropanoids and phytoquinoids from Illicium plants. Cancer Lett. 2004;214(2):165-9.

Meseguer M, Martinez-Conejero J, O'Connor J, Pellicer A, Remohí J, Garrido N. The significance of sperm DNA oxidation in embryo development and reproductive outcome in an oocyte donation program: a new model to study a male infertility prognostic factor. Fertil Steril. 2008;89(5):1191-9.

Mitchell RT, Saunders PT, Sharpe RM, Kelnar CJH, Wallace WHB. Male fertility and strategies for fertility preservation following childhood cancer treatment. Endocr Dev. 2009;15:10134.

Mohammed HH, Badawi ME, El-Tarabany MS, Rania M. Effects of boldenone undecylenate on growth performance, maintenance behaviour, reproductive hormones and carcass traits of growing rabbits. Pol J Vet Sci. 2016;19(2):245-51.

Mottram DR, George AJ: Anabolic steroids. Baillieres Best Pract Res Clin Endocrinol Metab. 2000;14(1):55-69.
Oda S, El-Ashmawy IM. Adverse effects of the anabolic steroid, boldenone undecylenate, on reproductive functions of male rabbits. Int J Exp Pathol. 2012;93(3):172-8.

Pitts SC, Davis M. An evidence-based analysis of anabolic steroids as performance enhancers in horses. Equine Vet Educ. 2007;19(7):388-91.

Purkayastha D, Mahanta B. Effect of nandrolone decanoate FSH, LH and testosterone. World J Life Sci Med Res. 2012; 2(3):123-7.

Saggu S, Sakeran M, Zidan N, Tousson E, Mohan A, Rehman H. Ameliorating effect of chicory (Chichorium intybus L.) fruit extract against 4-tert-octylphenol induced liver injury and oxidative stress in male rats. Food Chem Toxicol. 2014;72:138-46.

Salas-Ramirez KY, Montalto PR, Sisk CL. Anabolic steroids have long-lasting effects on male social behaviors. Behav Brain Res. 2010;208(2):328-35.

Saleh N, Waded E. Immune response following the administration of the anabolic steroid Boldenone Undecylenate in rabbits. Stem Cell. 2014;5:80-7.

Santos AF, Mendonca PH, Santos LA, Silva NF, Tavares, JKL. Anabolizantes: conceitos segundo praticantes de musculação em Aracaju (SE). Psicol Estudo. 2006;11(2):371-80.

Scarth JP, Kay J, Teale P, Akre C, Le Bizec B, De Brabander $\mathrm{HF}$, et al. A review of analytical strategies for the detection of 'endogenous' steroid abuse in food production. Drug Test Anal. 2012;4(Suppl 1):40-9.

Schmidt HA, Strimmer K, Vingronl M, von Haeseler A. Maximum likelihood phylogenetic analysis using quartets and parallel computing. Bioinformatics. 2002;18(3):502-4.

Shimomura K, Shimada M, Hagiwara M, Shimada M, Hagiwara M. Insights into testicular damage induced by ethinylestradiol in rats. Reprod Toxicol. 2005;20(1):157-63.

Silcox RW, Keeton JT, Johnson BH. Effects of zeranol and trenbolone acetate on testis function, live weight gain and carcass traits of bulls. J Anim Sci. 1986;63(2):358-68.

Simontacchi C, Perez de Altamirano T, Marinelli L, Angeletti $\mathrm{R}$, Gabai G. Plasma steroid variations in bull calves repeatedly treated with testosterone, nortestosterone and oestradiol administered alone or in combination. Vet Res Commun 2004;28(6):467-77. 
Singh G, Maurya S, Delampasona MP, Catalan C. Chemical constituents, antimicrobial investigation and antioxidative potential of volatile oil and acetone extract of star anise fruits. J Sci Food Agric. 2006; 86(1):111-21.

Takahashi M, Tatsugi Y, Kohno T. Endocrinological and pathological effects of anabolic-androgenic steroid in male rats. Endocr J. 2004;51(4):425-34.

Thabet NS, Abelrazek EM, Ghazy EM, Elballal SS. Effect of the anabolic steroids, boldenone undecylenate on reproductive performance of male rabbits. J Reprod Infertil. 2010;1(1):8-17.

Tousson E, El-Moghazy M, Massoud A, Akel A. Histopathological and immunohistochemical Changes in the testes of rabbits after injection with the growth promoter boldenone. Reprod Sci. 2012;19(3):253-9.

Tousson E, El-Moghazy M, Massoud A, El-Atrash A, Sweef O, Akel A. Physiological and biochemical changes after boldenone injection in adult rabbits. Toxicol Ind Health. 2016;32(1):17782.

Van Amsterdam J, Opperhuizen, A, Hartgens F. Adverse health effects of anabolic-androgenic steroids. Reg Toxicol Pharm. 2010;57(1):117-23.
Waljee AK, Rogers MA, Lin P, Singal AG, Stein JD, Marks RM, et al. Short term use of oral corticosteroids and related harms among adults in the United States: population based cohort study. BMJ. 2017;357(art.j1415):1-8.

Wang GW, Hu WT, Huang BK, Qin LP. Illicium verum: a review on its botany, traditional use, chemistry and pharmacology. J Ethnopharmacol. 2011; 136(1):10-20.

Wang YX, Sun Y, Feng W, Wang P, Yang P, Li J, et al. Association of urinary metal levels with human semen quality: a cross-sectional study in China. Environ Int. 2016;91:51-9.

World Health Organization. International Agency for Research on Cancer. IARC Monographs on the Evoluation on the carcinogenic risks to humans. [S.1.]: IARC; 1987. (Supplement 17). [cited Jun 15 2006] Available from: http://monographs.iarc. fr/ENG/Monographs/supp17/Supp17.pdf.

Zahran F, Tousson E, Shalapy M. Ameliorating effect of Ginkgo biloba and Moringa oleifera against Equigan induced testicular toxicity and oxidative stress in male rat. Am J Biol Chem. 2015;3(2):39-44.

Received for publication on $05^{\text {th }}$ June 2017 Accepted for publication on $30^{\text {th }}$ August 2017 